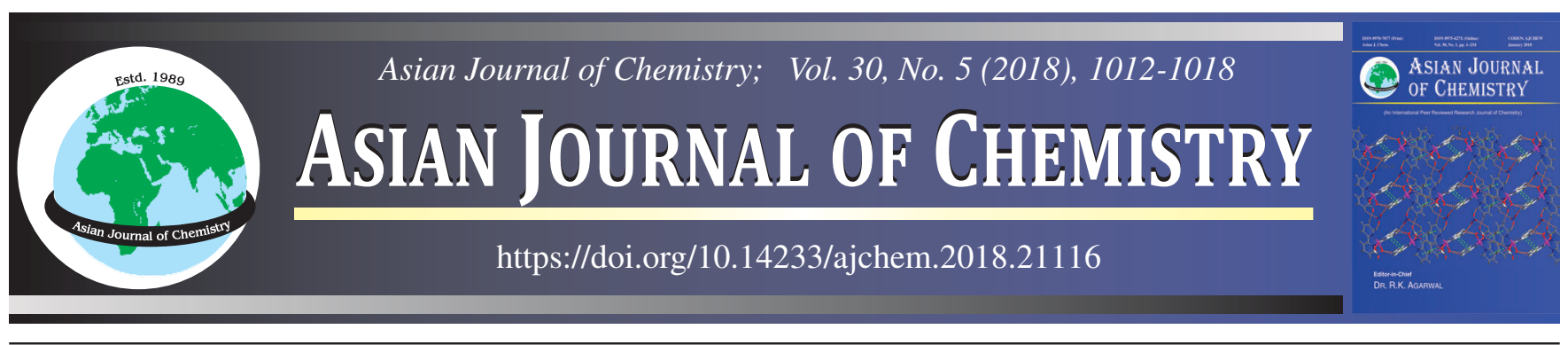

\title{
Investigation of Morphotropic Phase Boundary by Rietveld Refinement and Raman Spectroscopy for $(1-x)\left(\mathrm{Na}_{0.5} \mathrm{Bi}_{0.5}\right) \mathrm{TiO}_{3}-\mathrm{xBaTiO}_{3}$ Ceramics
}

\section{Mesrar ${ }^{1}$, T. Lamcharfi $^{1}$, N. Echatoui ${ }^{1, *}$, F. AbDi $^{1}$ and A. Harrach ${ }^{2}$}

${ }^{1}$ Signals, Systems and Components Laboratory, Faculty of Sciences and Technologies, Université Sidi Mohamed Ben Abdellah, B.P. 2202, Fez, Morocco

${ }^{2}$ Laboratory of Condensed Matter Chemistry, Faculty of Sciences and Technologies, Université Sidi Mohamed Ben Abdellah, B.P. 2202, Fez, Morocco

*Corresponding author: E-mail: nor-said.echatoui@usmba.ac.ma

\begin{abstract}
In this paper, the structural properties of $(1-\mathrm{x})\left(\mathrm{Na}_{0.5} \mathrm{Bi}_{0.5}\right) \mathrm{TiO}_{3}-\mathrm{xBaTiO}_{3}$ ceramic system for $(\mathrm{x}=0.00,0.03,0.05,0.06,0.07,0.08$ and 0.1$)$ were studied. Moreover, the samples are obtained through the conventional solid-state method. The effect of calcination temperature ranging from 800 to $1000{ }^{\circ} \mathrm{C}$ was investigated, using X-ray diffraction data and Rietveld refinement method, which permit to verify the morphotropic phase boundary at $\mathrm{x}=0.05-0.07$. The Raman spectral data were examined by inspecting the changes in their respective peak positions, full width at half maximum (FWHM) and intensities by increasing $\mathrm{BaTiO}_{3}$ composition. It was found that morphotropic phase boundary in the studied system resides at composition of $x=0.05$. The analysis of both Rietveld refinement and Raman spectroscopy of the samples showed a distortion of $\mathrm{Na}_{0.5} \mathrm{Bi}_{0.5} \mathrm{TiO}_{3}$ lattice when $\mathrm{Ba}^{2+}$ ions were added, as well as the ceramic structures underwent a gradual distortion by increasing the composition fraction of $\mathrm{BaTiO}_{3}$
\end{abstract}

Keywords: Sodium bismuth titanate, Rietveld refinement, Morphotropic phase boundary, Raman spectroscopy, X-ray diffraction.

ᄂ _ - - - - - - - - - - - - - - - - - - - - - - - - - -

\section{INTRODUCTION}

Sodium bismuth titanate (NBT) $\left(\mathrm{Na}_{0.5} \mathrm{Bi}_{0.5} \mathrm{TiO}_{3}\right)$ evokes a great interest due to its high promising dielectric and piezoelectric properties over a wide temperature range [1]. By owing to the environmental protection concern, sodium bismuth titanate is considered as a promising candidate in order to replace lead zirconate titanate (PZT)-based piezoelectric ceramic material [2]. Jones and Thomas [3] reported that NBT is included into the R3c space group symmetry of rhombohedral structure and shows unusual ferroelectric and dielectric properties. Recently, many studies by XRD also confirmed that results with $\left(\mathrm{a}_{\mathrm{H}}=\right.$ $5.4887 \AA$ and $\mathrm{CH}=13.5048 \AA$ ) revealed a random distribution of $\mathrm{Na}^{+}$and $\mathrm{Bi}^{3+}$ ions at 12 cubo-octahedral sites [3-5]. Sodium bismuth titanate is a relaxer perovskite $\left(\mathrm{ABO}_{3}\right)$ with A-site being equally occupied by two different cations, knowing that this specific property is rare in most of $\mathrm{ABO}_{3}$ perovskite. The relaxor behaviour of NBT is suggested to be due to cation disorder at $\mathrm{A}$-site $(\mathrm{Na} / \mathrm{Bi})[3,6]$, as also confirmed by neutron diffraction experiments [7]. Additionally, using transmission electron microscopy, several authors $[8,9]$ found that at room temperature, nano-scale tetragonal (P4bm) platelets exist into a rhombohedral (R3c) matrix. Moreover, single crystal experiments by Gorfman and Thomas [10] proposed that the average structure of NBT single crystals is not compatible with the rhombohedral system, but would be better represented by the monoclinic space group Cc. The structure of $\mathrm{Na}_{0.5} \mathrm{Bi}_{0.5} \mathrm{TiO}_{3}$ displays anti-phase (a-a-a-) octahedra tilting and shows a spontaneous polarization at the room temperature resulting from the cations displacements along the $[111]_{\mathrm{P}}$ (where $\mathrm{p}$ denotes pseudocubic) direction with remnant polarization value $\mathrm{Pr}=38 \mu \mathrm{C} /$ $\mathrm{cm}^{2}$ [11]. In this research, X-ray diffraction measurements of (1-x) $\left(\mathrm{Na}_{0.5} \mathrm{Bi}_{0.5}\right) \mathrm{TiO}_{3}-\mathrm{xBaTiO}_{3}$ for the different compositions ( $\mathrm{x}=0.00,0.03,0.05,0.06,0.07,0.08$ and 0.1$)$ synthesized by solid-state reaction route were studied. The objective of this study is the complementary use of Rietveld method for the reinvestigation of morphotropic phase boundary in $(1-\mathrm{x})\left(\mathrm{Na}_{0.5}\right.$ $\left.\mathrm{Bi}_{0.5}\right) \mathrm{TiO}_{3}-\mathrm{xBaTiO}_{3}$.

\section{EXPERIMENTAL}

$(1-\mathrm{x})\left(\mathrm{Na}_{0.5} \mathrm{Bi}_{0.5}\right) \mathrm{TiO}_{3}-\mathrm{xBaTiO}{ }_{3}$ ceramics witch $(\mathrm{x}=0,0.03$, $0.05,0.06,0.07,0.08$ and 0.1$)$ have been prepared by the conventional solid-state reaction method. It consists of mixing a stoichiometric amount of oxides $\left(\mathrm{Bi}_{2} \mathrm{O}_{3}, \mathrm{TiO}_{2}\right)$ with a high purity $(99.96 \%)$ and carbonates $\left(\mathrm{BaCO}_{3}, \mathrm{Na}_{2} \mathrm{CO}_{3}\right)$. These elements were homogenized by milling under acetone according to the 
general chemical equation by respecting the stoichiometric percentages in order to obtain the desired compositions (1-x) $\left(\mathrm{Na}_{0.5} \mathrm{Bi}_{0.5}\right) \mathrm{TiO}_{3}-\mathrm{xBaTiO}_{3}$. The equation of the solid solution studied is shown as:

\begin{aligned} $\mathrm{Na}_{2} \mathrm{CO}_{3}+\mathrm{Bi}_{2} \mathrm{O}_{3}+4 \mathrm{TiO}_{2} & \longrightarrow 4\left(\mathrm{Na}_{0.5} \mathrm{Bi}_{0.5}\right) \mathrm{TiO}_{3}+\mathrm{CO}_{2} \uparrow \\ \mathrm{Ba}_{2} \mathrm{CO}_{3}+\mathrm{TiO}_{2} & \longrightarrow 4 \mathrm{BaTiO}_{3}+\mathrm{CO}_{2} \uparrow \\$\hline$\left[(1-\mathrm{x}) / 4 \mathrm{Na}_{2} \mathrm{CO}_{3}+[(1-\mathrm{x}) / 4]\right. & \longrightarrow \begin{array}{l}(1-\mathrm{x})\left(\mathrm{Na}_{0.5} \mathrm{Bi}_{0.5}\right) \mathrm{TiO}_{3}-\mathrm{XBaTiO}_{3} \\ \mathrm{Bi}_{2} \mathrm{O}_{3}+\mathrm{xBaCO}_{3}+\mathrm{TiO}_{2}\end{array}\end{aligned}$

The calcination of sodium bismuth titanate $\left(\mathrm{Na}_{0.5} \mathrm{Bi}_{0.5} \mathrm{TiO}_{3}\right.$ or NBT) was carried out in air in a muffle furnace at different temperatures $\left(800,900\right.$ and $1000{ }^{\circ} \mathrm{C}$ ) for $4 \mathrm{~h}$, after that, the powders were dried and grounded with an agate mortar in the presence of few drops of $2 \%$ poly(vinyl alcohol) (PVA). The dried powders were pressed under uniaxial pressing so as to obtain pellets having a diameter of $10 \mathrm{~mm}$ and a thickness of about $1 \mathrm{~mm}$, under a pressure of 10 tons $/ \mathrm{cm}^{2}$ for $3 \mathrm{~min}$, then these pellets were sintered for $4 \mathrm{~h}$ at $1100^{\circ} \mathrm{C}$, this heat treatment temperature was selected on the basis of the recommendation expressed by several authors in order to have a maximum density [1,12-14]. The crystalline structure of the samples (1-x) $\left(\mathrm{Na}_{0.5} \mathrm{Bi}_{0.5}\right) \mathrm{TiO}_{3}-\mathrm{xBaTiO}_{3}$ was characterized by X-ray diffraction (XPERT-PRO with $\mathrm{CuK} \alpha$ radiation where $\lambda=1.5406 \AA$ ) and Raman spectroscopy which has been used as an effective technique to investigate the structural evolution in perovskite type solid solution ceramics. The lattice parameters were calculated by using a global refinement of the full diagram, with the pattern matching process of the Rietveld method (fullprof software).

\section{RESULTS AND DISCUSSION}

XRD characterization of $\mathrm{Na}_{0.5} \mathrm{Bi}_{0.5} \mathrm{TiO}_{3}$ (NBT) system: Fig. 1 shows the XRD patterns obtained for the calcined $\mathrm{Na}_{0.5} \mathrm{Bi}_{0.5}$ $\mathrm{TiO}_{3}$ compound at various temperatures $(800,900$ and 1000 ${ }^{\circ} \mathrm{C}$ ) during $4 \mathrm{~h}$. The formation of NBT perovskite phase $\left(\mathrm{ABO}_{3}\right)$ start at $800{ }^{\circ} \mathrm{C}$, with the simultaneous appearance of a few secondary phases impurity. However, the intensity of the peaks corresponding to these phases decreases approximately at 900 ${ }^{\circ} \mathrm{C}$ and disappears completely at $1000{ }^{\circ} \mathrm{C}$, which justifies the increases in the degree of crystallinity of the NBT compound.

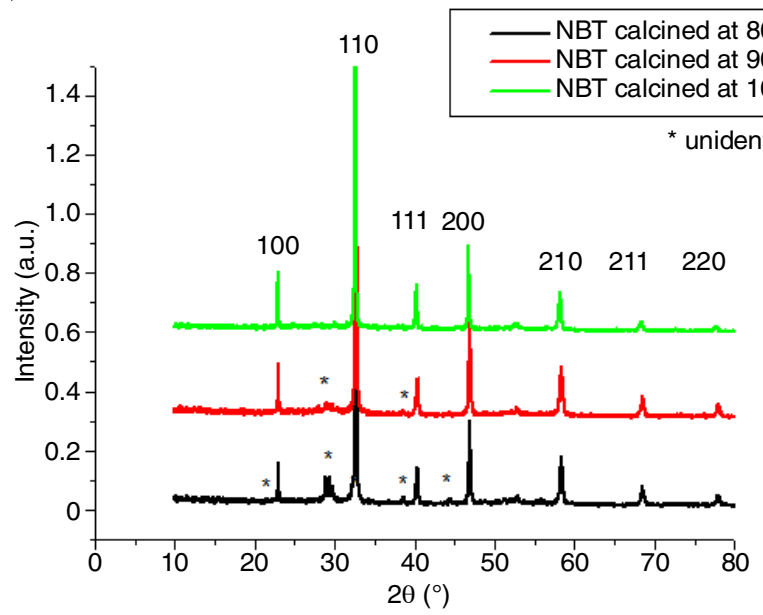

Fig. 1. X-ray diffraction pattern of $\mathrm{Na}_{0.5} \mathrm{Bi}_{0.5} \mathrm{TiO}_{3}$ powder calcined at different temperatures $\left(800,900\right.$ and $\left.1000{ }^{\circ} \mathrm{C}\right)$
Fig. 2 shows the refined $\mathrm{X}$-ray diffraction pattern of $\mathrm{Na}_{0.5} \mathrm{Bi}_{0.5} \mathrm{TiO}_{3}$ calcined at $1000^{\circ} \mathrm{C}$. This refinement was adjusted using the Fullprof program and peak shapes which were described by pseudo-Voigt profiles. For better overall refinement, the space group R3c was used, in the calculated patterns and the difference of patterns showed that this matches the experimental data closely $[15,16]$. Rietveld refinement revealed the crystallization of NBT in the rhombohedral phase in R3c space group and lattice parameters are $[\mathrm{a}=5.4917 \AA, \mathrm{c}=13.4773 \AA$, $\alpha=90, \beta=90, \gamma=120$ and $V=352.004 \mathrm{~A}^{3}$, (hexagonal axes)].

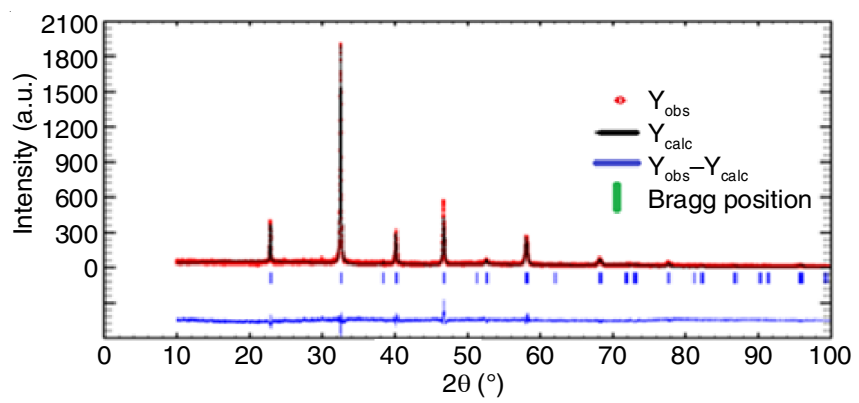

Fig. 2. Rietveld refinement for the compound $\mathrm{Na}_{0.5} \mathrm{Bi}_{0.5} \mathrm{TiO}_{3}$ with space group $\mathrm{R} 3 \mathrm{c}$

Fig. 3 shows the projection of the rhombohedral structure in the direction [001] which represents the oxygen octahedral of NBT structure, the cations $\mathrm{A}\left(\mathrm{Na}^{+} / \mathrm{Bi}^{3+}\right)$ as well as the cations $\mathrm{B}\left(\mathrm{Ti}^{4+}\right)$, are not situated respectively at the center of cuboctahedral and octahedral cavities, this suggests the cationic displacement. Based on the model proposed by Jones and Thomas [3], these displacements follow the polar axis direction $[111]_{\mathrm{p}}(\mathrm{p}$ denotes pseudo-cubic) equivalent to the $c$-axis of hexagonal structure, combined with opposite rotation of adjacent oxygen octahedral corresponding to the system of tilts [17]. Gorfman and Thomas [10] confirmed the previous observations by revealing deformation from the ideal structure R3c. Besides, the theoretical Goldschmidt factor $(t=0.903)$ plays an essential role in the phase transition of the system. Given that $\mathrm{t}<1$, light distortions are expected in the structure of NBT, it is therefore probable that this observed local disorder is due to the difference between $\mathrm{Na}^{+}$ ionic radius $\left(\mathrm{r}_{\mathrm{N}^{+}}=1.39 \AA\right)$ and $\left(\mathrm{r}_{\mathrm{B}^{3}}=1.45 \AA\right)$ causing distortions of octahedral $\left[\mathrm{NaO}_{6}\right]$ and $\left[\mathrm{BiO}_{6}\right]$ clusters. Table- 1 shows the anisotropic displacement factors $\mathrm{U}_{\mathrm{ij}}$, which noticed that the value of bismuth exhibits a greater anisotropic thermal vibration than sodium. Also, high anisotropic thermal vibration values were observed for oxygen. Thus, the anisotropic displacement factors of anionic lattice are significantly larger than those of cationic lattice. We concluded from the results that the simultaneous presence of octahedra tilts and cations displacements, suggested the existence of a local disorder between $\mathrm{Na}^{+}$and $\mathrm{Bi}^{3+}$ cations $[3,4,18]$. These results are in a good agreement with the work of several researchers $[3,10,19]$.

\begin{tabular}{ccccccc}
\multicolumn{8}{c}{ TABLE-1 } \\
\multicolumn{7}{c}{ PARAMETERS OF ANISOTROPIC DISPLACEMENT } \\
\hline $\begin{array}{c}\text { Atom } \\
\text { species }\end{array}$ & $\mathrm{U} 11$ & $\mathrm{U} 22$ & $\mathrm{U} 33$ & $\mathrm{U} 12$ & $\mathrm{U} 31$ & $\mathrm{U} 23$ \\
\hline $\mathrm{Na}$ & 0.0217 & 0.0108 & 0.000 & 0.0217 & 0.0359 & 0.000 \\
$\mathrm{Bi}$ & 0.0359 & 0.0177 & 0.000 & 0.0359 & 0.0908 & 0.000 \\
$\mathrm{Ti}$ & 0.0108 & 0.0060 & 0.000 & 0.0108 & 0.0088 & 0.000 \\
$\mathrm{O}$ & 0.0309 & 0.0140 & -0.0108 & 0.0060 & 0.0480 & -0.004 \\
\hline
\end{tabular}




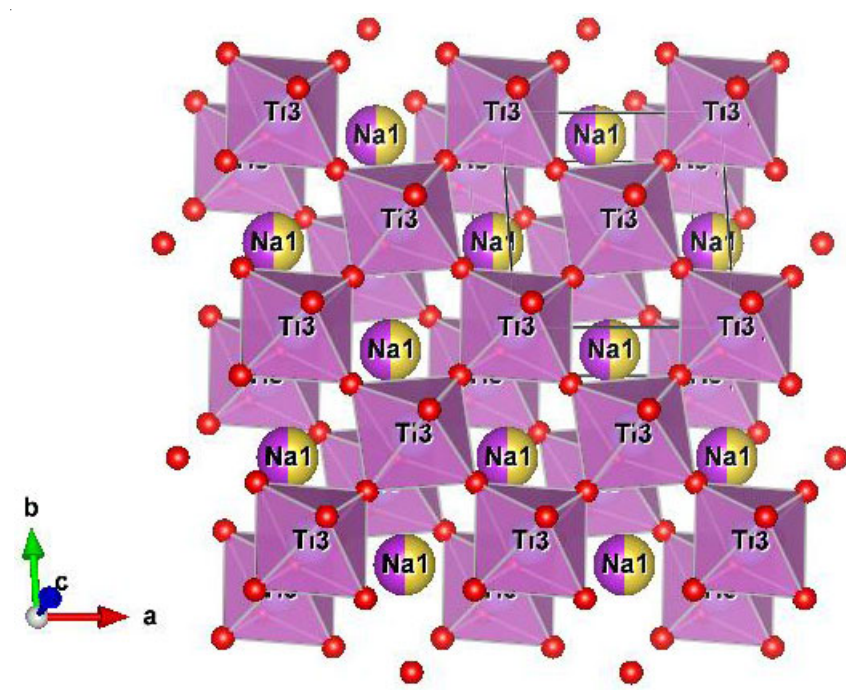

Fig. 3. Representation of oxygen octahedra of the NBT structure

Influence of additive amount of $\mathrm{BaTiO}_{3}$ : Fig. 4(a) shows the $\mathrm{X}$-ray diffractograms of $(1-\mathrm{x})\left(\mathrm{Na}_{0.5} \mathrm{Bi}_{0.5}\right) \mathrm{TiO}_{3}-\mathrm{xBaTiO}$ ceramics with $(\mathrm{x}=0.00,0.03,0.05,0.06,0.07,0.08$ and 0.1$)$, sintered at $1100{ }^{\circ} \mathrm{C}$ for $4 \mathrm{~h}$. The XRD patterns indicate the formation of pure perovskite phase without any trace of secondary phase peaks, which confirm the complete solid solution formation between $\mathrm{Na}_{0.5} \mathrm{Bi}_{0.5} \mathrm{TiO}_{3}$ and $\mathrm{Ba}^{-\mathrm{TiO}_{3}}$ systems [20]. Fig. 4(b) shows the XRD peak splitting in the $2 \theta$ range of $46^{\circ}-47^{\circ}$ for various compositions. These peaks are indexed as $(200)_{\mathrm{R}}$ and $(002)_{\mathrm{T}}$ corresponds to rhombohedral and tetragonal phases, respectively and confirmed the existence of morphotropic transformation phase (MPB) around $\mathrm{x}=0.05$ which is in good agreement with the literature [21,22]. However, increase of the doping rate up to $x=0.08$ causes the fusion of these peaks, which explains the disappearance of the symmetry (rhomboedral + tetragonal) and the emergence of tetragonal phase [18]. Moreover, a slight and low shift of the peak is observed by increasing $\mathrm{BaTiO}_{3}$, this can be justified by the ionic radii $\left(\mathrm{r}_{\mathrm{Bi}}{ }^{3+}\right.$ $=1.45 \AA)$ and $\left(\mathrm{r}_{\mathrm{Na}^{+}}=1.39 \AA\right)$, which are smaller than $\left(\mathrm{r}_{\mathrm{Ba}^{2+}}=\right.$ $1.61 \AA$ ) [23]. Similar changes were also observed by other researchers also [24-26].

Rietveld refinement analysis: Structural refinement was carried out for $(1-\mathrm{x})\left(\mathrm{Na}_{0.5} \mathrm{Bi}_{0.5}\right) \mathrm{TiO}_{3}-\mathrm{xBaTiO}_{3}$ ceramics with $(\mathrm{x}=0.00,0.03,0.05,0.06,0.07,0.08$ and 0.1$)$ using Rietveld refinement method [27]. Fitted profiles of NBT.BT were obtained using Fullprof software as shown in Fig. 5. Table-2 summarizes the lattice parameters and the fraction phase wt. (\%) in two principal phases observed in these samples. Various symmetries of spatial groups were tested by increasing compound $(\mathrm{x})$ for (1-x)NBT-xBT solid-solutions.

(i) For compounds around $x=0$ and 0.03 , the results showed that the refined profile corresponds well to the experimental data with only spatial group R3c (rhombohedral). Thus, the value of the lattice parameters (a) and (c) show a slight increase

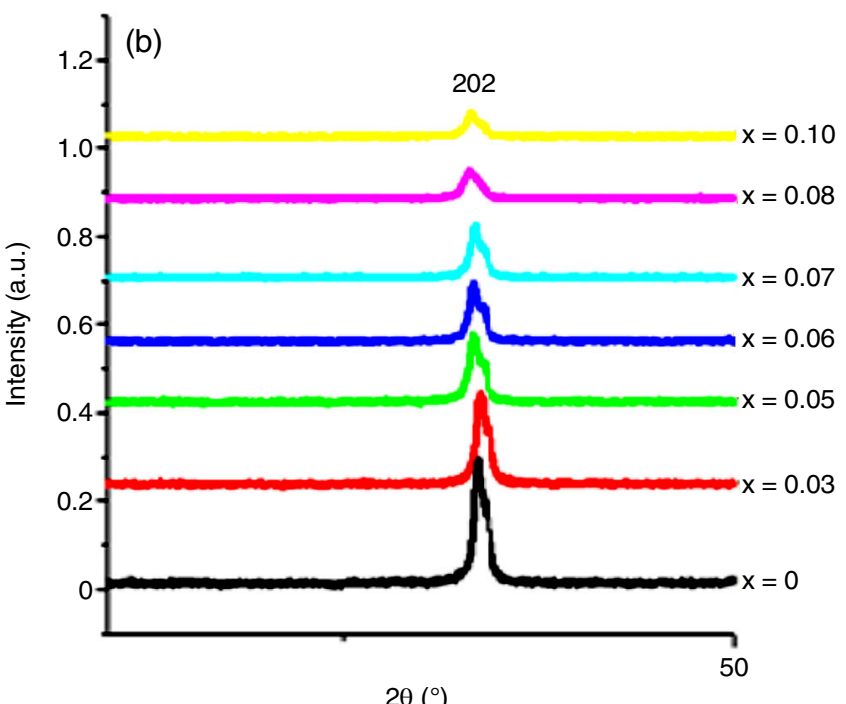

$2 \theta\left({ }^{\circ}\right)$

Fig. 4. (a) X-ray diffraction pattern of the powder (1-x) $\left(\mathrm{Na}_{0.5} \mathrm{Bi}_{0.5}\right) \mathrm{TiO}_{3}-\mathrm{xBaTiO}_{3}$; (b) Zoom of the peak (202) in the $2 \theta$ range of $46-47^{\circ}$

TABLE-2

STRUCTURAL PARAMETERS OF $(1-\mathrm{x})\left(\mathrm{Na}_{0.5} \mathrm{Bi}_{0.5}\right) \mathrm{TiO}_{3}-\mathrm{xBaTiO}_{3}$ OBTAINED FROM THE RIETVELD REFINEMENT

\begin{tabular}{cccccccc}
\hline Composition & $\mathrm{Rp}(\%)$ & Group spatial & Phase fraction $(\%)$ & $\mathrm{a}(\AA)$ & $\mathrm{b}(\AA)$ & $\mathrm{c}(\AA)$ & $\alpha / \beta / \gamma$ \\
\hline $\mathrm{X}=0$ & 8.67 & $\mathrm{R} 3 \mathrm{c}$ & 100 & 5.4915 & 5.4915 & 13.4756 & $90 / 90 / 120$ \\
\hline $\mathrm{X}=0.03$ & 8.65 & $\mathrm{R} 3 \mathrm{c}$ & 100 & 5.4960 & 5.4960 & 13.5020 & $90 / 90 / 120$ \\
\hline \multirow{2}{*}{$\mathrm{X}=0.05$} & \multirow{2}{*}{8.28} & $\mathrm{R} 3 \mathrm{c}$ & 74.325 & 5.5080 & 5.5080 & 13.5162 & $90 / 90 / 120$ \\
& & $\mathrm{P} 4 \mathrm{bm}$ & 25.675 & 5.4975 & 5.4975 & 3.9001 & $90 / 90 / 90$ \\
\hline \multirow{2}{*}{$\mathrm{X}=0.06$} & $\mathrm{R} 3 \mathrm{c}$ & 70.087 & 5.5130 & 5.5130 & 13.5168 & $90 / 90 / 120$ \\
& \multirow{2}{*}{8.17} & $\mathrm{P} 4 \mathrm{bm}$ & 29.913 & 5.5149 & 5.5149 & 3.9001 & $90 / 90 / 90$ \\
\hline \multirow{2}{*}{$\mathrm{X}=0.07$} & \multirow{2}{*}{7.34} & $\mathrm{R} 3 \mathrm{c}$ & 73.256 & 5.5182 & 5.5182 & 13.5198 & $90 / 90 / 120$ \\
& & $\mathrm{P} 4 \mathrm{bm}$ & 26.744 & 5.5154 & 5.5154 & 3.9007 & $90 / 90 / 90$ \\
\hline $\mathrm{X}=0.08$ & 8.35 & $\mathrm{P} 4 \mathrm{bm}$ & 100 & 5.5109 & 5.5109 & 3.902 & $90 / 90 / 90$ \\
\hline $\mathrm{X}=0.10$ & 8.75 & $\mathrm{P} 4 \mathrm{bm}$ & 100 & 5.5223 & 5.5223 & 3.8944 \\
\hline
\end{tabular}



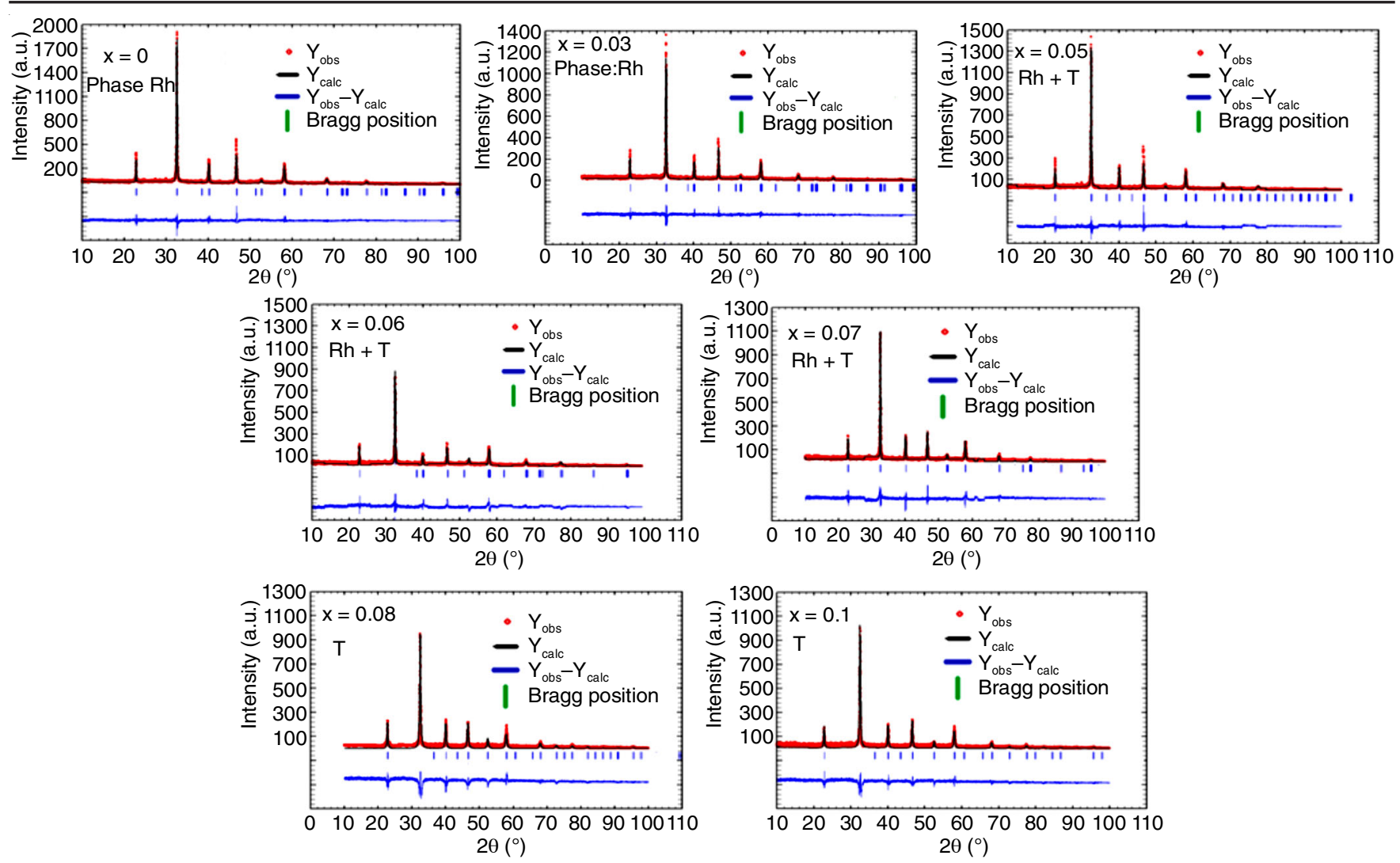

Fig. 5. Rietveld refinement for compounds $(1-\mathrm{x})\left(\mathrm{Na}_{0.5} \mathrm{Bi}_{0.5}\right) \mathrm{TiO}_{3}-\mathrm{xBaTiO}_{3}$ calcined at $1000{ }^{\circ} \mathrm{C}$

by increasing of $\mathrm{BaTiO}_{3}$ content $(5.4915 \AA$ for $\mathrm{x}=0$ to 5.4960 $\AA$ for $\mathrm{x}=0.03$ ), (from $13.4756 \AA$ for $\mathrm{x}=0$ to $13.5020 \AA$ for $\mathrm{x}=0.03$ ), respectively (Table-2).

(ii) For compounds around $\mathrm{x}=0.05$ and 0.07 , Rietveld refinement revealed a mixture of tetragonal $(\mathrm{P} 4 \mathrm{bm})$ and rhombohedral (R3c) crystalline phases. Thus, the refined data did fit well with the experimental data for this range. The result indicates that $0.95 \mathrm{NBT}-0.05 \mathrm{BT}$ is composed of $74.325 \%$ rhombohedral phase and $25.675 \%$ tetragonal phase (Table-2), these results confirmed the existence of morphotropic transformation phase (MPB) in the NBT-BT system. Moreover, the values of the parameters (a) and (c) remain increasing. These results were consistent with the XRD analysis [28].

(iii) On further refinement for range ( $\mathrm{x}=0.08$ and $\mathrm{x}=$ 0.1 ), a tetragonal structure with space group $\mathrm{P} 4 \mathrm{bm}$ was found to fit well. Thus, structure phase transition from (rhombohedral + tetragonal) to tetragonal takes place with increasing $\mathrm{x}$. The characteristics of phase structure transition were in good agreement with those reported in the literature [29].

The refined profiles confirm the successful formation of NBT-BT phase during the calcination process. The refined lattice parameters indicate good agreement between the experimentally observed and theoretical calculated display ( $\mathrm{Y}_{\mathrm{obs}}$ $\left.Y_{\text {calc }}\right)$. These results are in a good agreement with the reported work $[23,28,29]$.

Raman spectral studies: Fig. 6 shows the evolution of the Raman spectra at room temperature of compound (1-x) $\left(\mathrm{Na}_{0.5} \mathrm{Bi}_{0.5}\right) \mathrm{TiO}_{3}-\mathrm{xBaTiO}_{3}$ for different compositions $(\mathrm{x}=0.00$, $0.03,0.05,0.06,0.07,0.08$ and 0.1 ), performed in the range from 100 to $1000 \mathrm{~cm}^{-1}$. All the Raman bands of $\mathrm{Na}_{0.5} \mathrm{Bi}_{0.5} \mathrm{TiO}_{3}$ ceramic have a relatively broad feature, this can be attributed

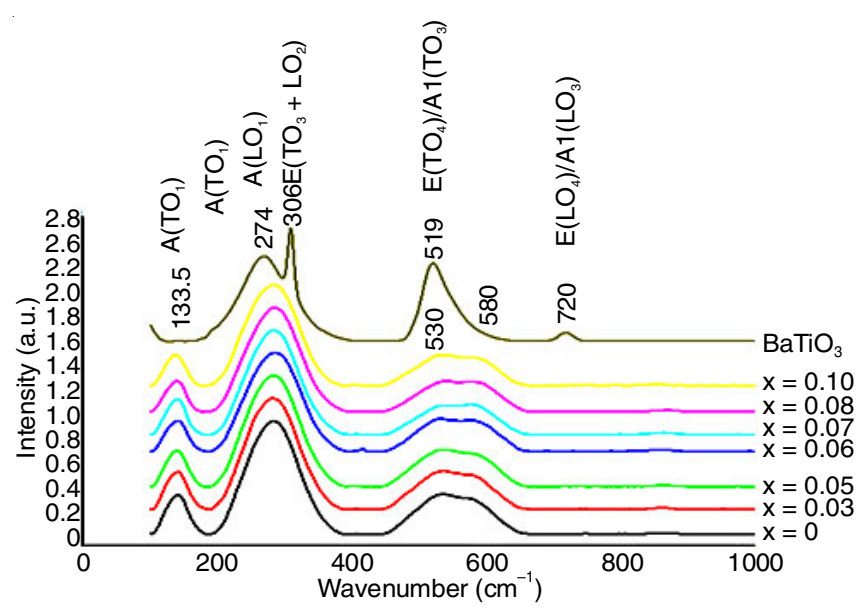

Fig. 6. Raman spectra of $(1-\mathrm{x})\left(\mathrm{Na}_{0.5} \mathrm{Bi}_{0.5}\right) \mathrm{TiO}_{3}-\mathrm{xBa}-\mathrm{TiO}_{3}$ ceramics with different compositions

to A-site disorder [30]. The $\mathrm{Na}_{0.5} \mathrm{Bi}_{0.5} \mathrm{TiO}_{3}$ system having the rhombohedral structure with R3c symmetry, shows 13 Raman active optical phonon modes in irreducible representation $\Gamma_{\text {vib }}$ $=4 \mathrm{~A}_{1}+9 \mathrm{E}[31]$ and the general irreducible representations of $\mathrm{BaTiO}_{3}$ for tetragonal structure, are as follows: $\Gamma_{\text {vib }}=3 \mathrm{~F}_{1 \mathrm{u}}$ $+\mathrm{F}_{2 \mathrm{u}}$, as per the group theory analysis. Thus, we can observe four modes in $\mathrm{C}_{4 \mathrm{v}}$ point group, which are: $\Gamma_{\mathrm{c} 4 \mathrm{v}}=3\left(\mathrm{~A}_{1}+\mathrm{E}\right)+$ $\mathrm{E}+\mathrm{B}_{1}$ [32]. The vibration modes were illustrated in Fig. 6, it can be seen for both $\mathrm{Na}_{0.5} \mathrm{Bi}_{0.5} \mathrm{TiO}_{3}$ and $\mathrm{BaTiO}_{3}$ samples that Raman peaks appear at 137.47, 280.86, 530, 580 and 866 $\mathrm{cm}^{-1}$, while for $\mathrm{BaTiO}_{3}$ based sample Raman peak appear at $274,306,519$ and $720 \mathrm{~cm}^{-1}$. These results are in a good agreement with Suchanicz et al. [33] and Lidjici et al. [34]. The first Raman active A1(TO1) mode located at the frequency 
$133.47 \mathrm{~cm}^{-1}$ is related to the vibration of A-O site and to distorted octahedral $\left[\mathrm{BiO}_{6}\right]$ and $\left[\mathrm{NaO}_{6}\right]$ clusters [33]. The second Raman active $\mathrm{E}\left(\mathrm{TO}_{2}\right)$ mode centered at around $280 \mathrm{~cm}^{-1}$ can be deconvoluted in three Raman peaks at 240.95, 280.52 and 306.21 $\mathrm{cm}^{-1}$ and is observed in many perovskite materials [33]. This band is very sensitive to all structural transitions and is dominated by a stretching correspond to Ti-O bonds due to the presence of octahedral $\left[\mathrm{TiO}_{6}\right]$ clusters at short-range. Modes $\left(\mathrm{TO}_{3}\right)$ observed at around 520 and $580 \mathrm{~cm}^{-1}$ is assigned to $(\mathrm{O}-\mathrm{Ti}-\mathrm{O})$ stretching symmetric vibrations of octahedral $\left[\mathrm{TiO}_{6}\right]$
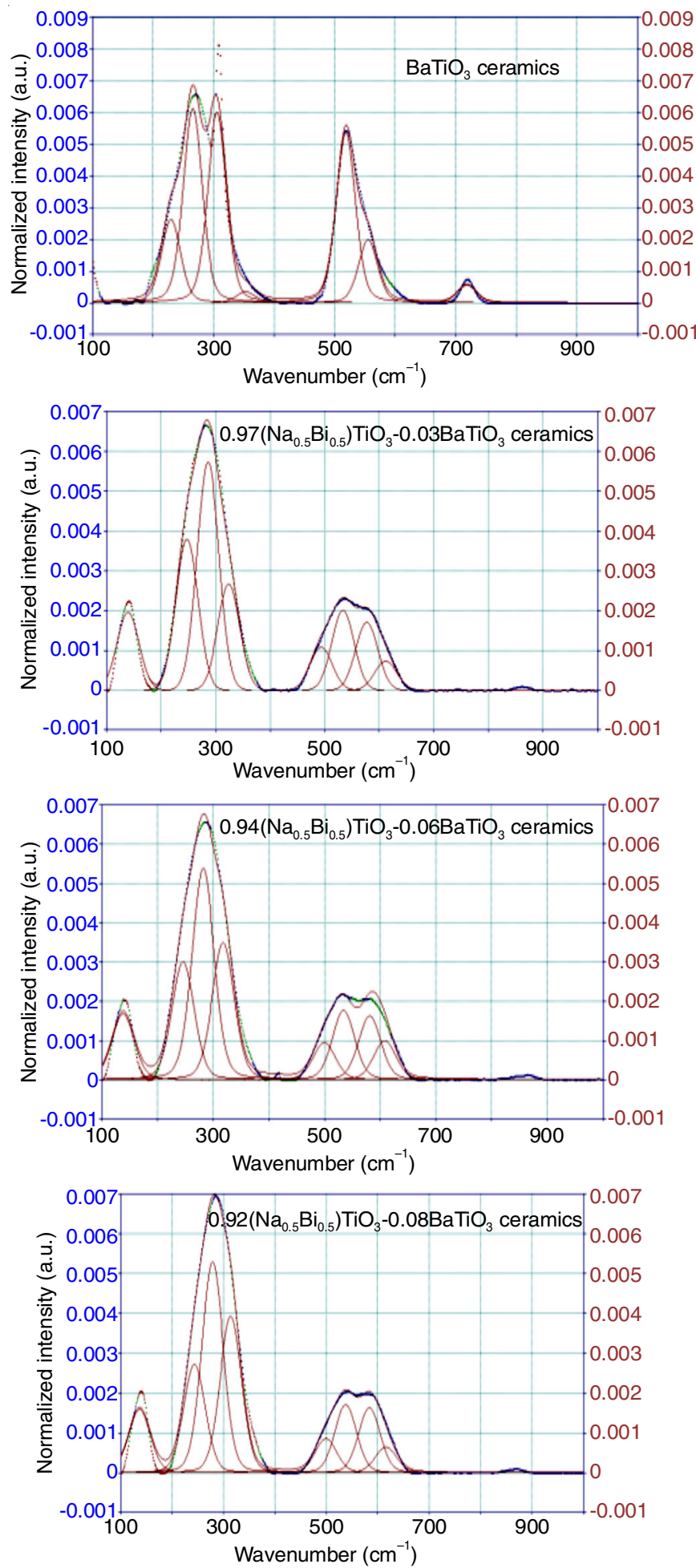

clusters [34]. The latest mode (i.e. at $866 \mathrm{~cm}-1$ ) can be correlated to the presence of oxygen vacancies [34].

In order to better understand the spectral evolution, we have carried out deconvolution of pure $\mathrm{Na}_{0.5} \mathrm{Bi}_{0.5} \mathrm{TiO}_{3}$ spectrum with Peakfit software using Gauss and Lorentzian area function as shown in Fig. 7. Moreover, for a better overall deconvolution, attempts to use three peaks for the broad feature at 200 to 300 $\mathrm{cm}^{-1}$ and four peaks for that of 400 to $600 \mathrm{~cm}^{-1}$ in $\mathrm{Na}_{0.5} \mathrm{Bi}_{0.5} \mathrm{TiO}_{3}$ were found.
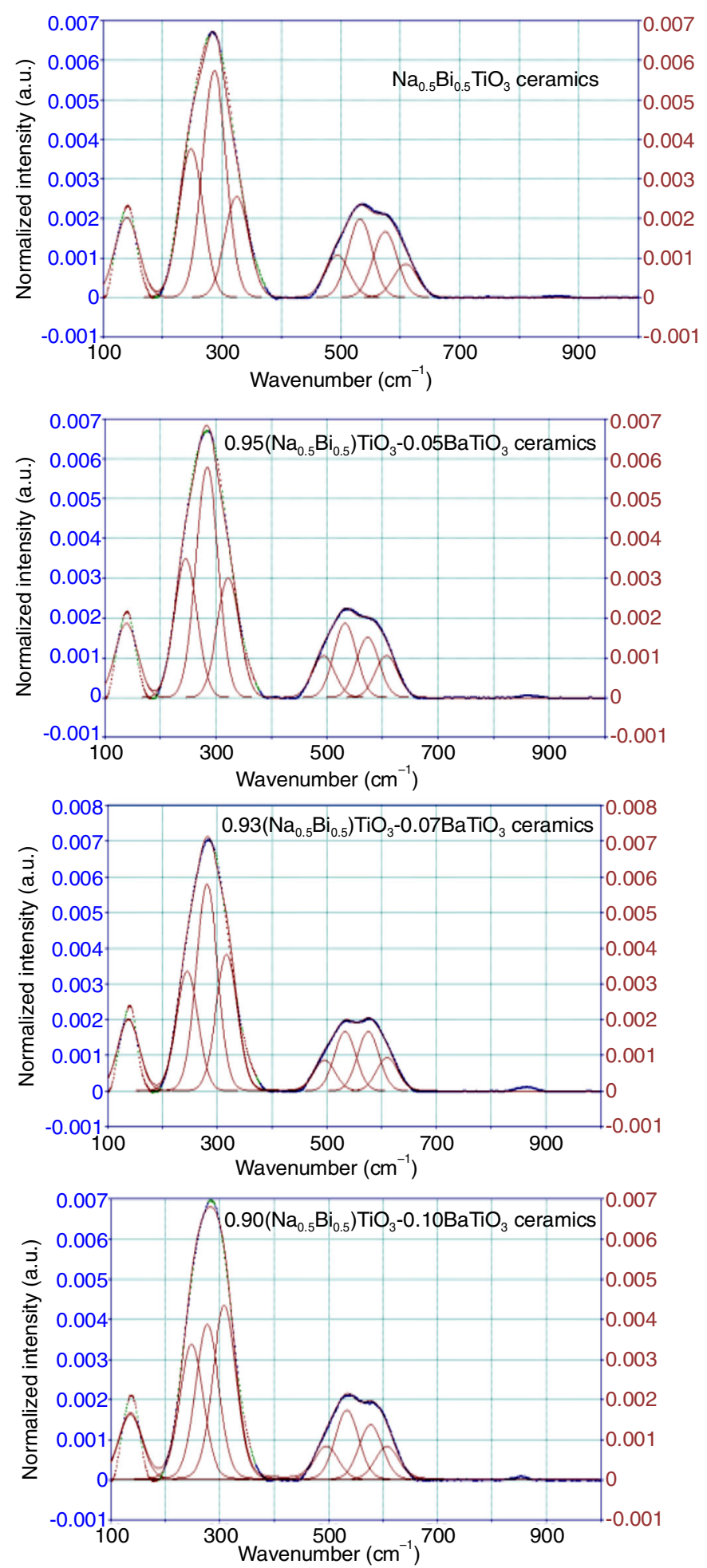

Fig. 7. The deconvoluted Raman spectra of $(1-\mathrm{x})\left(\mathrm{Na}_{0.5} \mathrm{Bi}_{0.5}\right) \mathrm{TiO}_{3}-\mathrm{xBaTiO}_{3}$ ceramics with different compositions 
(i) For the first mode (i.e. at $137 \mathrm{~cm}^{-1}$ ), there is a general upward shift of Raman frequencies.

(ii) The broadband centered around $280 \mathrm{~cm}^{-1}$ is split into three modes (i.e. at 240,280 and $306 \mathrm{~cm}^{-1}$ ), this is also true for all samples, the last mode at $306 \mathrm{~cm}^{-1} \mathrm{E}\left(\mathrm{TO}_{3}+\mathrm{LO}_{2}\right)$ is a characteristic peak of the tetragonal symmetry of $\mathrm{BaTiO}_{3}$ in Raman spectra. The intensity of this peak has not only increased but also shifted to the higher wavenumbers and this is well observed from the composition of $x=0.05$. From these observations, we can inferred the existence of morphotropic phase starting at $\mathrm{x}=0.05$.

(iii) The overlapping bands at $400-650 \mathrm{~cm}^{-1}$ are split into four modes (i.e. at 420, 520, 580 and $610 \mathrm{~cm}^{-1}$ ) and presents two relatively prominent peaks (i.e. at 520 and $580 \mathrm{~cm}^{-1}$ ). The features clearly demonstrate a change in the phonon behaviour in the compound (1-x) $\left(\mathrm{Na}_{0.5} \mathrm{Bi}_{0.5}\right) \mathrm{TiO}_{3}-\mathrm{xBaTiO}_{3}$ solid solution.

For more thorough study, the overall variation of position frequency and full width at half maximum (FWHM) of individual peaks are plotted in Fig. 8. When $\mathrm{BaTiO}_{3}$ composition of (x) is added in $\mathrm{Na}_{0.5} \mathrm{Bi}_{0.5} \mathrm{TiO}_{3}$ structure, a remarkable changes are observed in Raman spectra. The position of mode around 137 $\mathrm{cm}^{-1}$ assigned to $\mathrm{A} 1\left(\mathrm{TO}_{1}\right)$ symmetry, which is associated with $\mathrm{Na}-\mathrm{O}$ vibration, displays a shift to the lower frequencies as the composition ( $\mathrm{x}$ ) increases (up to about $133.2 \mathrm{~cm}^{-1}$ for $\mathrm{x}=$ 0.06 ). Moreover, this mode present a minimum around $x=$ 0.06 (Fig. 8a). In addition, the FWHM revealed a sudden drop in the frequency around the composition of $\mathrm{x}=0.05$ and then remains mostly unchanged (Fig. 7b). The broad band centered at $280 \mathrm{~cm}^{-1}$ presents a shift to the high frequencies as the composition ( $\mathrm{x}$ ) increases (up to about $286 \mathrm{~cm}^{-1}$ for $\mathrm{x}=0.06$ ). Moreover, the FWHM shows an anomaly at $\mathrm{x}=0.06$ and presents a minimum with a further increase in composition (x). The band $\left(\mathrm{TO}_{3}\right)$ centered around $534 \mathrm{~cm}^{-1}$ shows similar changes to $\mathrm{E}\left(\mathrm{TO}_{2}\right)$ band and the FWHM starts to widen around the composition $\mathrm{x}=0.05$. The position and FWHM band $137 \mathrm{~cm}^{-1}$ revealed a remarkable changes when the (x) composition of $\mathrm{BaTiO}_{3}$ increases for $\mathrm{x}=0.06$. In addition, with the increase in $\mathrm{Ba}$, the band at $280 \mathrm{~cm}^{-1}$ shifted to the higher wavenumber Fig. 8(a), which was caused by expansion of the unit and reduced $\mathrm{Ti}-\mathrm{O}$ bond with $\mathrm{Ba}^{2+}$ diffusing into the lattice.

These results were consistent with the XRD analysis. Finally, we observed that the position and FWHM of all the modes show a similar type of anomaly at $\mathrm{x}=0.06$. On the basis of these considerations, it is possible to conclude that the rhombohedral-tetragonal phase co-exists at $\mathrm{x}=0.06$, which is also observed in XRD studies [33,35,36].

\section{Conclusion}

The (1-x) $\left(\mathrm{Na}_{0.5} \mathrm{Bi}_{0.5}\right) \mathrm{TiO}_{3}-\mathrm{xBaTiO}$ lead-free solid solutions were obtained by solid state reaction technique. All the samples exhibited perovskite phase with no secondary impurity. A gradual change in crystalline structure with bismuth titanate concentration was observed. The morphotropic phase boundary was investigated by Rietveld refinement method, which confirmed the existence of structural change around of the composition $\mathrm{x}$, between 0.05 and 0.07 . Rietveld refinement revealed a gradual structural distortion that was related to cations $\left(\mathrm{Na}^{+} / \mathrm{Bi}^{3+}\right)$ in A-site. The characteristic bands in the Raman spectra were observed and discussed in accordance with the structural changes in terms of the peaks frequency, intensity and FWHM as $\mathrm{BaTiO}_{3}$ concentration increased.

\section{REFERENCES}

1. T. Takenaka, K. Maruyama and K. Sakata, Jpn. J. Appl. Phys., 30, 2236 (1991);

https://doi.org/10.1143/JJAP.30.2236.

2. K. Reichmann, A. Feteira and M. Li, Materials, 8, 8467 (2015); https://doi.org/10.3390/ma8125469.
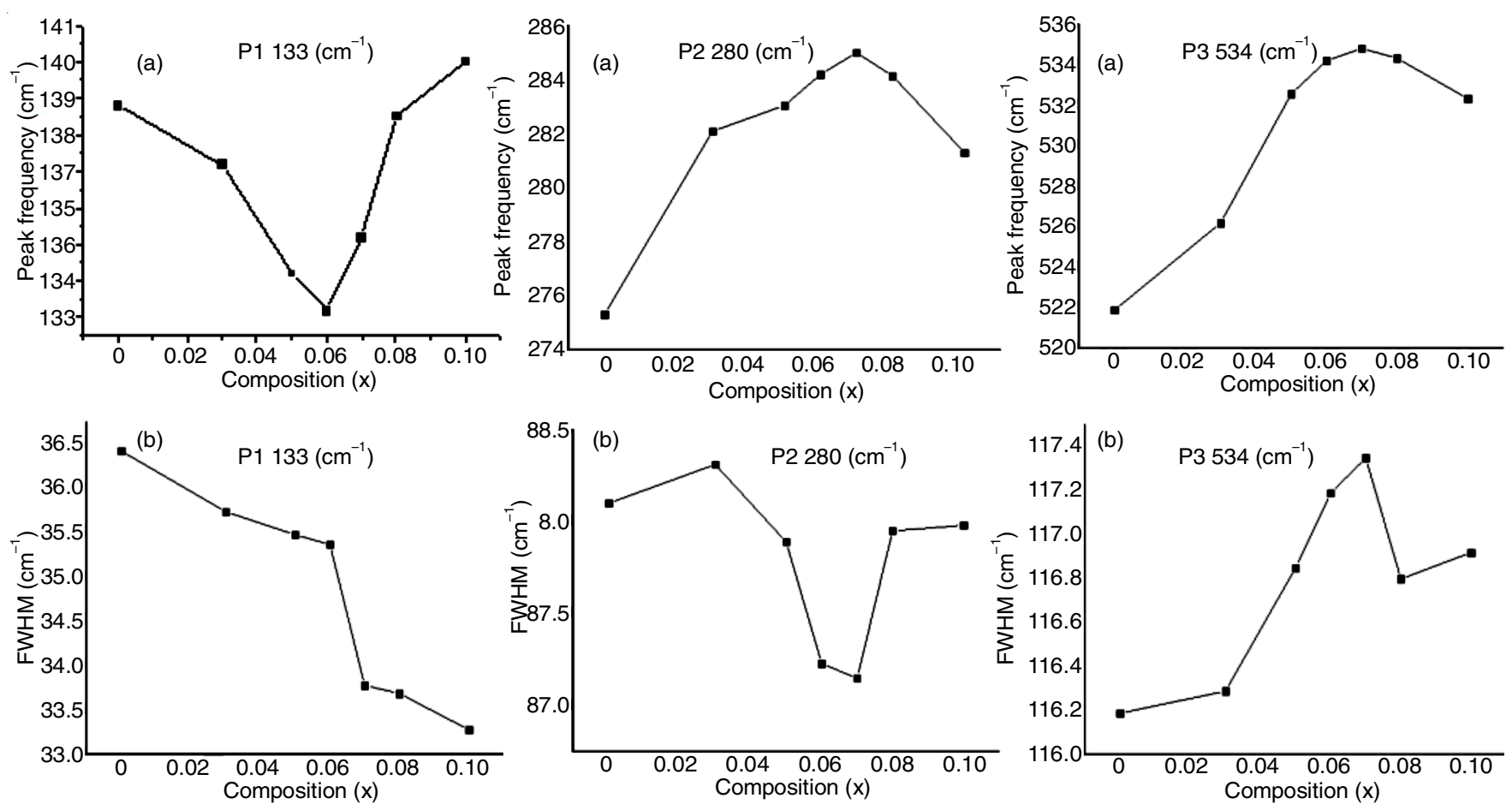

Fig. 8. Variations of (a) the peak positions and (b) FWHM of different modes in the Raman spectra 
3. G.O. Jones and P.A. Thomas, Acta Crystallogr. B, 58, 168 (2002); https://doi.org/10.1107/S0108768101020845.

4. N.D. Scarisoreanu, R. Birjega, A. Andrei, M. Dinescu, F. Craciun and C. Galassi, ed.: A. Peláiz-Barranco, Phase Transitions, Dielectric and Ferroelectric Properties of Lead-free NBT-BT Thin Films, In: Advances in Ferroelectrics, InTech, Chap. 16 (2012).

5. A. Sasaki, T. Chiba, Y. Mamiya and E. Otsuki, Jpn. J. Appl. Phys., 38, 5564 (1999); https://doi.org/10.1143/JJAP.38.5564.

6. M.K. Niranjan, T. Karthik, S. Asthana, J. Pan and U.V. Waghmare, J. Appl. Phys., 113, 194106 (2013); https://doi.org/10.1063/1.4804940.

7. J.A. Zvirgzds, P.P. Kapostin, J.V. Zvirgzde and T.V. Kruzina, Ferroelectrics, 40, 75 (1982); https://doi.org/10.1080/00150198208210600.

8. G. Trolliard and V. Dorcet, Chem. Mater., 20, 5074 (2008); https://doi.org/10.1021/cm800464d.

9. V. Dorcet, G. Trolliard and P. Boullay, Chem. Mater., 20, 5061 (2008); https://doi.org/10.1021/cm8004634.

10. S. Gorfman and P.A. Thomas, J. Appl. Cryst., 43, 1409 (2010); https://doi.org/10.1107/S002188981003342X

11. K.S. Rao, K.C.V. Rajulu, B. Tilak and A. Swathi, Nat. Sci., 2, 357 (2010).

12. P. Marchet, E. Boucher, V. Dorcet and J.P. Mer-curio, J. Eur. Ceram. Soc., 26, 3037 (2006);

https://doi.org/10.1016/j.jeurceramsoc.2006.02.024.

13. J. Suchanicz and T.V. Kruzina, Mater. Sci. Eng. B, 178, 889 (2013); https://doi.org/10.1016/j.mseb.2013.04.011.

14. Y. Sun, H. Liu, H. Hao, S. Zhang, L. Guo and Z. Yu, Ceram. Int., 38, S41 (2012); https://doi.org/10.1016/j.ceramint.2011.04.045.

15. Q. Xu, S. Chen, W. Chen, S. Wu, J. Lee, J. Zhou, H. Sun and Y. Li, J. Alloys Compd., 381, 221 (2004); https://doi.org/10.1016/j.jallcom.2004.02.057.

16. Q. Xu, S. Chen, W. Chen, S. Wu, J. Lee, J. Zhou, H. Sun and Y. Li, J. Alloys Compd., 381, 221 (2004); https://doi.org/10.1016/j.jallcom.2004.02.057.

17. A.M. Glazer, Acta Crystallogr. B, 28, 3384 (1972); https://doi.org/10.1107/S0567740872007976.

18. M. Ogino, Y. Noguchi, Y. Kitanaka, M. Miyayama, C. Moriyoshi and Y. Kuroiwa, Crystals, 4, 273 (2014); https://doi.org/10.3390/cryst4030273.

19. E. Aksel, J.S. Forrester, J.L. Jones, P.A. Thomas, K. Page and M.R. Suchomel, Appl. Phys. Lett., 98, 152901 (2011); https://doi.org/10.1063/1.3573826.

20. C. Xu, D. Lin and K.W. Kwok, Solid State Sci., 10, 934 (2008); https://doi.org/10.1016/j.solidstatesciences.2007.11.003.

21. R. Ranjan and A. Dviwedi, Solid State Commun., 135, 394 (2005); https://doi.org/10.1016/j.ssc.2005.03.053.
22. X. Zhou, C. Jiang, H. Luo, C. Chen, K. Zhou and D. Zhang, Ceram. Int., 42, 18631 (2016); https://doi.org/10.1016/j.ceramint.2016.08.208.

23. S. Sasikumar, R. Saravanan, S. Saravanakumar and K. Aravinth, J. Mater. Sci.: Mater. Electron., 29, 1198 (2018); https://doi.org/10.1007/s10854-017-8022-Z.

24. J.U. Rahman, A. Hussain, A. Maqbool, G.H. Ryu, T.K. Song, W.-J. Kim and M.H. Kim, J. Alloys Compd., 593, 97 (2014); https://doi.org/10.1016/j.jallcom.2014.01.031.

25. A. Hussain, C.W. Ahn, J.S. Lee, A. Ullah and I.W. Kim, Sens. Actuators Phys., 158, 84 (2010); https://doi.org/10.1016/j.sna.2009.12.027.

26. S.J. Kuang, X.G. Tang, L.Y. Li, Y.P. Jiang and Q.X. Liu, Scr. Mater, 61, 68 (2009); https://doi.org/10.1016/j.scriptamat.2009.03.016.

27. H.M. Rietveld, J. Appl. Cryst., 2, 65 (1969); https://doi.org/10.1107/S0021889869006558.

28. Q. Xu, Z. Song, W. Tang, H. Hao, L. Zhang, M. Appiah, M. Cao, Z. Yao, Z. He and H. Liu, J. Am. Ceram. Soc., 98, 3119 (2015); https://doi.org/10.1111/jace.13693.

29. P.S. Silva, J.C.C.A. Diaz, O. Florêncio, M. Venet and J.C. M'Peko, Arch. Metall. Mater, 61, (2016); https://doi.org/10.1515/amm-2016-0008

30. K.K. Mishra, V. Sivasubramanian, R.M. Sarguna, T.R. Ravindran, A.K. Arora, D.K. Aswal and A.K. Debnath, AIP Conf. Proc., 1313, 174 (2010); https://doi.org/10.1063/1.3530481.

31. J. Petzelt, S. Kamba, J. Fabry, D. Noujni, V. Porokhonskyy, A. Pashkin, I. Franke, K. Roleder, J. Suchanicz, R. Klein and G.E. Kugel, J. Phys. Condens. Matter, 16, 2719 (2004); https://doi.org/10.1088/0953-8984/16/15/022.

32. J. Kreisel, A.M. Glazer, G. Jones, P.A. Thomas, L. Abello and G. Lucazeau, J. Phys. Condens. Matter, 12, 3267 (2000); https://doi.org/10.1088/0953-8984/12/14/305.

33. J. Suchanicz, I. Jankowska-Sumara and T.V. Kruzina, J. Electroceram., 27, 45 (2011); https://doi.org/10.1007/s10832-011-9648-5.

34. H. Lidjici, B. Lagoun, M. Berrahal, M. Rguitti, M.A. Hentatti and H. Khemakhem, J. Alloys Compd., 618, 643 (2015); https://doi.org/10.1016/j.jallcom.2014.08.161.

35. J. Petzelt, S. Kamba, J. Fábry, D. Noujni, V. Porokhonskyy, A. Pashkin, I. Franke, K. Roleder, J. Suchanicz, R. Klein and G.E. Kugel, J. Phys. Condens. Matter, 16, 2719 (2004); https://doi.org/10.1088/0953-8984/16/15/022.

36. E. Buixaderas, S. Kamba, J. Petzelt, J. Drahokoupil, F. Laufek and M. Kosec, Appl. Phys. Lett., 91, 112909 (2007); https://doi.org/10.1063/1.2783962. 